\title{
اتجاهات طلبة كلية التربية نحو مهنة التدريس بمدينة مصراتة
}

أ. ربيعة أحمد كيم

كلية الآداب-- جامعة مصراتة

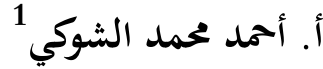

كلية الآداب- جامعة مصراتة

https://doi.org/10.36602/faj.2018.n12.07

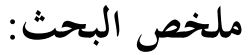

تحددت مشكلة البحث في السؤال الرئيسي الآتي: ما ابتحاتات طلبة الكلية التربية نحو مهنة التدريس؟ وما علاقتها بمتغير الجنس؟، ويتفرع من هذا السؤال عدة أسئلة، ويهدف البحث الحالي إلى:

1- التعرف على ابتحاهات طلبة كلية التربية نحو مهنة التدريس وعلاقتها بمتغير الجنس.

2- التعرف على الاتحاهات لطلبة كلية التربية حول النظرة الشخصية للمهنة.

3- التعرف على الاتحاهات الإيجابية لطلبة كلية التربية نحو السمات الشخصية للأستاذ.

4- التعرف على الاتجاهات الإيجابية لطلبة كلية التربية نحو التقييم الشخصي لقدراته الخاصة. 5- التعرف على الاتجاهات الإيجابية لطلبة كلية التربية نحوَ مستقبل المهنة.

6- التعرف على الاتحاهات الإيجابية لطلبة كلية التربية نحو نظرة المجتمع للمهنة. ولتحقيق هذه الأهداف استخدم الباحثان المنهج الوصفي لملاءمته لِطَبيعة البحث الحالي، وتم اعتماد مقياس (مهدي أحمد الطاهر) المطبق في المملكة العربية السعودية، للعام الجامعي لهي (1991م)؛ لقياس ابتحاهات المعلمين نحو مهنة التدريس، وقد أسفرت نتائج البحث عن وجود ابتاهات إيجابية لطلبة كلية التربية نحو مهنة التدريس، إلا أن ابتاهات الإناث نحو مهنة التدريس أكثر من الذكور، وفي ضوء نتائج البحث أوصى الباحثان ببعض التوصيات والمقترحات.

الكلمات المفتاحية: الاتجاهات التربوية، السمات الشخصية للمعلم، مهنة التدريس.

${ }^{1}$ ahmedalshoki@art.misuratau.edu.ly 


\section{Abestract}

Teaching is described as one of important occupations and which plays an essential role in the prosperity of a society. If this job has not been promoted, there will not be specialists or experts in the different life aspects and all the society basic needs will be difficult to meet. In regard to this teachers' goals and students' attributes and needs had better be considered. The current study aims to find out the attributes of Faculty of Education students towards teaching as an occupation and how gender difference can affect the students' attributes. This study is significant as it might provide the students positive views about teaching. Also, the results of the study may help teachers to perform more effectively. Educational instructions may benefit from this study findings as they can be a benchmark or a criterion to have a reasonable knowledge of the students' attributes. To analyze the data of the study, the researcher used some statistical tools which were Ttest, Percentage, the Mean and Standard deviation. The findings of the study revealed that Faculty of Education students have positive attitudes towards teaching. However, it appears that female students outweigh the male students.

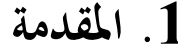

أصبح الاهتمام بالعملية التعليمية اليوم ضرورة حتمية؛ لما لها من أهمية بالغة في حياة

الفرد والمجتمع وتحديد مكانته الاجتماعية، فالمعلم يعد ركيزة مهمة في العملية التعليمية،

وأحد مدخلاتما الأساسية التي تسهم في تحسين منتج هذه العملية، فرسالة المعلم رسالة واسعة يجب ألا تقتصر على الناحية العلمية فقط، بل تتعداها إلى العناية الصحيحة بالطلبة من جميع الجوانب (كريم واخرون،2008، ص5)، وتعد مهنة التدريس من أكثر المهن وأهمها في المجتمع؛ لأها تمثل الديمومة والاستمرارية في الحياة، فمهنة التدريس هي التي تحرك المؤسسة، وتجعلها تدور في فلك تقدم وتطور المجتمعات، ودون هذه المهمة لا توجد مدارس 140 https://misuratau.edu.ly/journal/arts 
أو كليات ولا طلبة، وبالتالي لا رافد للمجتمع لإشباع حاجاته الأساسية من متخصصين وخبراء في شتى المجالات، (أبو الضبعان، قطيشات، 2007، ص5)، فمهمة التعليم تعد من أعظم المهن قدرًا، وأكثرها أثرًاً في حياة الأفراد والجماعات؛ إذ يتوقف نوع المجتمع على لى الأفراد الذين يتم تكوينهم في مؤسسات التنشئة الاجتماعية (المجيدل،الشريع، 2012، 5). الجامعة مسؤولة عن إعداد الكفاءات الفردية وتنمتيها وتطويرها، فالجامعة ليست مكانا لتلقي المعارف والعلوم، أو لإجراء التجارب والاختبارات فقط، بل هي ميدان تفاعل واحتكاك اجتماعي وثقافي وتعاطف بين أعضاء الجامعة التي ترتادها، وباعتبار التعليم الجامعي يمتل مكانه مهمه في التعليم، وقد تعين خبرات الطلاب المتراكمة في مجالات الدراسة والامتحانات، كما يمثل طلبة الجامعة أهم الأطراف البشرية التي يتوقع أن تقوم بدور قيادي وتنموي في المجتمع مستقبلا (حمادي، وطحان، 1996، ص2-3). يعرف جميع الناس مهمة الأستاذ، وإن كان معظمهم يعتقد أن عمله سهل وهين، ولا يدرك صعوبة ما يقوم به الأستاذ داخل القاعة وخارجها، وأن عمله لا ينتهي بانتهاء اليوم الدراسي، بل يستمر حتى داخل منزله استكمالا لما يقوم به داخل الكلية، هذا بالإضافة إلى أنّ الأستاذ الناجح يظل ذهنه مشغولا في إعداد محاضراته اليومية إعدادا ذهنيًا، وقد وضع الإسلام معايير خاصة للمعلم المسلم، وضوابط خاصة بالتدريس، ومقرراته التي يحل للمسلم دراستها وإجادتما، وحرّمت عليه الكثير مما يبعده عن الصراط القويم، والرسول- صلى الله عليه وسلم- أوضح طريق المعلم في الإسلام في قوله: "من سلك طريقا يطلب فيه علما سلك إليه به طريقا من طرق الجنة، وإن الملائكة تضع أجنحتها رضا لطالب العلم، وإن العالم ليستغفر له من في السماوات والأرض والحيثان في جوف الماء، وإن فضل العالم على العابد كفضل القمر ليلة البدر على سائر الكواكب، وإن العلماء ورثة 
الأنبياء، وإن الأنبياء لم يورثوا دينارًا ولا درهًا، وإنما ورثو العلم، فمن أخذه أَخَذَ بحظ وافر

$$
\text { (أبو الهيجاء،2003، ص21-19). }
$$

إن الاتحاه ظاهرة تتكون وتنمو في مجرى حياة الفرد، وخلال ذلك يمر بعدد من

المراحل، فالناس لا يولدون ولديهم ابتحاهات معينة نحو التدريس، أو أي موضوعات مختلفة، بل يكسبوفا تدريجيَّا من خلال الملاحظة والاشتراط الإجرائي والاستجابي من خلال الأنماط المعرفية للتعلم، وكل هذه المؤثرات تكون متداخلة في الحبرة الواحدة (زين الدين، 2004، ص4)، واتجاهات المعلم نحو مهنته من أهم العوامل التي تساعده على إنجاز كثير من الأهداف، وهذا يدعو إلى حسن اختيار الطلبة الملتحقين بالكليات، بناء على رغباقم وابتحاهاتم نحو مهنة التدريس منناحية، وتدعيم وتنمية هذه الاتحاهات من ناحية أخرى. (الطاهر، 1991، 16)، ونظرا لامتلاك الطلبة ابتحاهات إيجابيه نحو مهنة التدريس باعتبار ذلك أحد المؤشرات المهمة في نجاحهم مستقبلا، وهذا مايسعى إليه البحث الحالي، فقد أجريت دراسات عديدة في بلدان مختلفة، اهتمت بالتعرف على امتلاكهم ابتحاتات نحو مهنتهم، حيث أظهرت نتائج دراسة الغامدي (1995)، العجمي (2007)، المجيد والشريع (2012) امتلاك الطلبة المعلمين ابتحات قوية، وكشفت نتائج دراستي الركابي ومحمد، (2002)، ودراسة عبدالفتاح (2010) امتلاكهم ابتحاهات ضعيفة، في الوقت الذي أظهرت دراسة الركابي ومحمد (2002) عدم امتلاك الطلبة ابتحات نحو مهنة التدريس، وأظهرت نتائج دراستي الغامدي (1995) والطاهر (1991) عدم وجود أثر للتخصص في ابحاهات الطلبة المعلمين نحو مهنة التدريس، وأشارت دراسة توفيق شاهين (1990)، ودراسة يوسف الأحرش (1996) إلى وجود فروق ذات دلالة إحصائية في الاتحاه نحو مهنة التدريس تبعًا لمتغير الجنس، ولصالح الطالبات والمعلمات، وأشارت دراسة 
توفيق شاهين (1990)، ودراسة يوسف الأحرش (1996) إلى وجود فروق ذات دلالة إحصائية في الاتحاه نحو مهنة التدريس تبعًا لمتغير الجنس، ولصالح الطالبات والمعلمات

$$
\text { (الإناث) (ورد في: حسن، 2014، صن 13). }
$$

\section{1}

يعد موضوع ابتحاهات الطلبة نحو مهنة التدريس من الموضوعات المهمة التي شغلت بال العديد من التربويين والباحثين، وخاصة أن مهنة التدريس تعد من المهن التي لها أهمية كبيرة في إعداد أجيال المستقبل التي تأخذ على عاتقها مهمة تطوير المجتمع وبنائه، وباعتبار أن الطلبة أحد العناصر الرئيسة في المجتمع الجامعي، الذي لابد له أن يتضمن الكثير من الأحداث والمواقف الاجتماعية والثقافية والنفسية، فقد شعر الباحثان بالمشكلة من خلال دراستهما وتدريسهما ، وبما أننا من ضمن الأساتذة الذين يعلمون طلاب هذه المرحلة، فقد تعرفنا على الكثير من الطلبة من مختلف الأقسام بالكلية، والذين يملكون ابتاهات مختلفة نحو مهنة التدريس، مما دفع الباحثان إلى إجراء مقابلة مع بعض الطلبة بكلية التربية، ومن مختلف الأقسام التي تمدف إلى معرفة رغبة الطلبة نحو ممارسة مهنة التدريس بعد التخرج، وكانت إجابات بعض الطلبة متفاوته، منهم غير الراغبين في ممارسة مهنة التدريس، وهناك طلبة راغبون في ممارستها بعد التخرج، كما هدفت المقابلة أيضًا معرفة سبب عدم رغبة بعض الطلبة عن ممارسة مهنة التدريس بعد التخرج من الكلية، فأجاب أغلب الطلبة بعدة أسباب، تتمثل في قولمم: عدم حصول أغلب الطلبة على فرصة عمل في مجال التدريس، وقلة الحوافز المادية التي تمنح إلى المعلمين، كما تعلّ بعض الطلبة بأن مهنة التدريس فرضت عليهم رغمًا عنهم، وأجاب بعضهم بإجبار والديهم على دراسة تخصص لا يرغبونه، كذلك أن المعلم أصبح يسند إليه أعباء إضافية لا علاقة لما بمهام عمله، ويفترض 
أن يقوم بها آخرون، وهذا ما دفع الباحثين إلى إجراء هذا البحث للتعرف على ابتاهات الطلبة نهو مهنة التدريس، وتأسيسًا على ما سبق، تحددت مشكلة البحث في السؤال الآتي: ما ابحاهات طلبة كلية التربية نحو مهنة التدريس بمدينة مصراتة؟

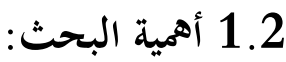

في ضوء ما يتوقع للبحث الحالي يمكن القول بأنه يفيد في المجالات الآتية:

1. يمكن أن يفيد في تقديم بعض التوصيات والمقترحات لإدارة الكلية، من أجل المساهمة في نجاح العملية التعليمية وتطويرها.

2. يمكن أن تفيد نتائج هذا البحث في معرفة دور الاتجاهات وأهميتها في نجاح المعلم/ الأستاذ في مهنته، وأدائهه لدوره برغبة وإتقان.

3. إن نتائج هذا البحث يمكن أن تفيد في الكشف عن الابحاهات الإيجابية لطلبة الكلية لمهنة التدريس، ويمكن أن تقدم مؤشرًا للقائمين على مؤسسات التعليم بالجامعة، بأن يأخذوا هذه الاتحاهات بعين الاعتبار؛ لما له من تأثير على الطلبة واقبالهم على

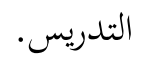
4. يمكن أن يشكل هذا البحث في الكشف عن أصول ومبادئ العمل لمهنة التدريس علي أسس علمية وموضوعية ومنهجية.

\section{1}

ما ابتحاهات طلبة كلية التربية نحو مهنة التدريس وعلاقتها بمتغير الجنس؟

هل توجد فروق بين عينتي الذكور والإناث في نظرة المجتمع نحو المهن؟

هل توجد فروق بين عينتي الذكور والإناث في نظرةم للسمات الشخصية للأستاذ؟ 
هل توجد فروق بين عينتي الذكور والإناث في نظرقم للتقييم الشخصي لقدراته

$$
\text { الخاصة؟ }
$$

هل توجد فروق بين عينتي الذكور والإناث في نظرتم لمستقبل المهنة؟

1

يهدف البحث إلى التعرف على الاتحاهات الإيجابية لطلبة كلية التربية نحو نظرة

$$
\text { المجتمع للمهنة. }
$$

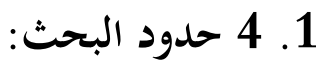

$$
\text { تحدد البحث الحالي فيما يلي: }
$$

- الحدود البشرية: تم إجراء البحث الحالي على عينة من طلبة كلية التربية في جميع التخصصات بمدينة مصراتة.

- الحدود المكانية: تم إجراء البحث الحالي بكلية التربية - جامعة مصراتة. - الحدود الزمنية: تم إجراء البحث الحالي خلال العام الجامعي 2017-2018م. 1

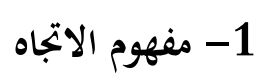

يعرف بأنه: "حالة داخلية تؤثر في اختيار الفرد للسلوك، أو عدم السلوك، حيال موضوع أو شخص أو شيء معين... كما يعرف الابحاه بأنه: استجابة عامة عند الفرد

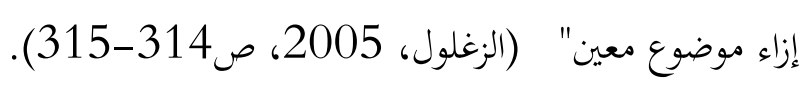

$$
\text { التعبيف الإجرائي للاتجاه }
$$


استجابة قبول أو رفض أفراد عينة البحث لمهنة التدريس، وتقاس بالدرجة التي يتحصل عليها الطلبة في استبانة الاتحاه نحو مهنة التدريس المطبقة في هذا البحث، والمكون من الأبعاد الآتية: النظرة الشخصية نهو المهنة- السمات الشخصية للمدرس- التقييم الشخصي لقدراته الخاصة - مستقبل المهنة- نظرة المجتمع نخو المهنة.

2- مهنة التدريس: عمل مهني راقي يتطلب نوعا من القدرات الفنية التي يمكن تحقيقها عن طريق إعداد مهني خاص، يشتمل على إعداد أكاديمي وتدريب عملي. (booth-3rb.blogspot.com)

\section{- التعريف الإجرائي لاتجاه نهو مهنة التدريس}

ويتبنى الباحثان التعريف الإجرائي للباحث عبد الحكيم محمد حسن بأنه: شعور

وجداني لدى طلبة كلية التربية، يقوم على معرفته وإدراكه بالمعتقدات والأفكار عن مهنة التدريس، ويتم التعبير عن هذا الشعور بالموافقة بشدة أو الموافق أو غير متأكد أو عدم الموافقة أو عدم الموافقة الشديدة للمواقف المكونة للاستبانة، التي بمجموعها تعكس ابتاهه نخو المهنة، وتقاس بالدرجة التي يكصل عليها طلبة كلية التربية من استجابته على الاستبانة المستخدمة لغرض هذا البحث (حسن، 2014، ص6).

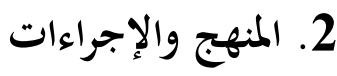

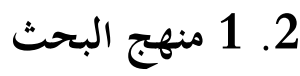

اعتمد الباحثان على المنهج الوصفي لملاءمته لطبيعة البحث الحالي، وهو منهج يعد من أكثر المناهج شيوعًا وانتشارا؛ نظرًا لِمَا يَتميَّز به من التوصل إلى الحقائق الدقيقة والظروف القائمة، ويعرف المنهج الوصفي بأنه "المنهج الذي يهتم بتحديد الظروف والعلاقات التي توجد بين الوقائع والحقائق، ويهتم بتحديد الحقائق والممارسات الشائعة 
والسائدة، والتعرف على المعتقدات والاتجاهات عند الأفراد والجماعات وطرائقها في النمو

$$
\begin{aligned}
& \text { والتطور" (مرسي، 1993، ص270). } \\
& \text { 2. } 2 \text { مجتمع البحث: }
\end{aligned}
$$

يتكون مجتمع البحث من جميع طلبة كلية التربية بمدينة مصراتة البالغ عددهم

$$
\text { (3325) - (33) طالب وطالبة. }
$$

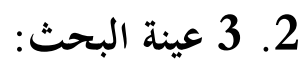

تكونت عينة البحث من (106) طالب وطالبة، تم اختيارهم بطريقة العينة العشوائية الطبقية المتساوية والمتناسبة من بجتمع البحث، والجدول التالي يوضح ذلك. شكل 1 يوضح النسبة المئوية لجميع التخصصات بكلية التربية

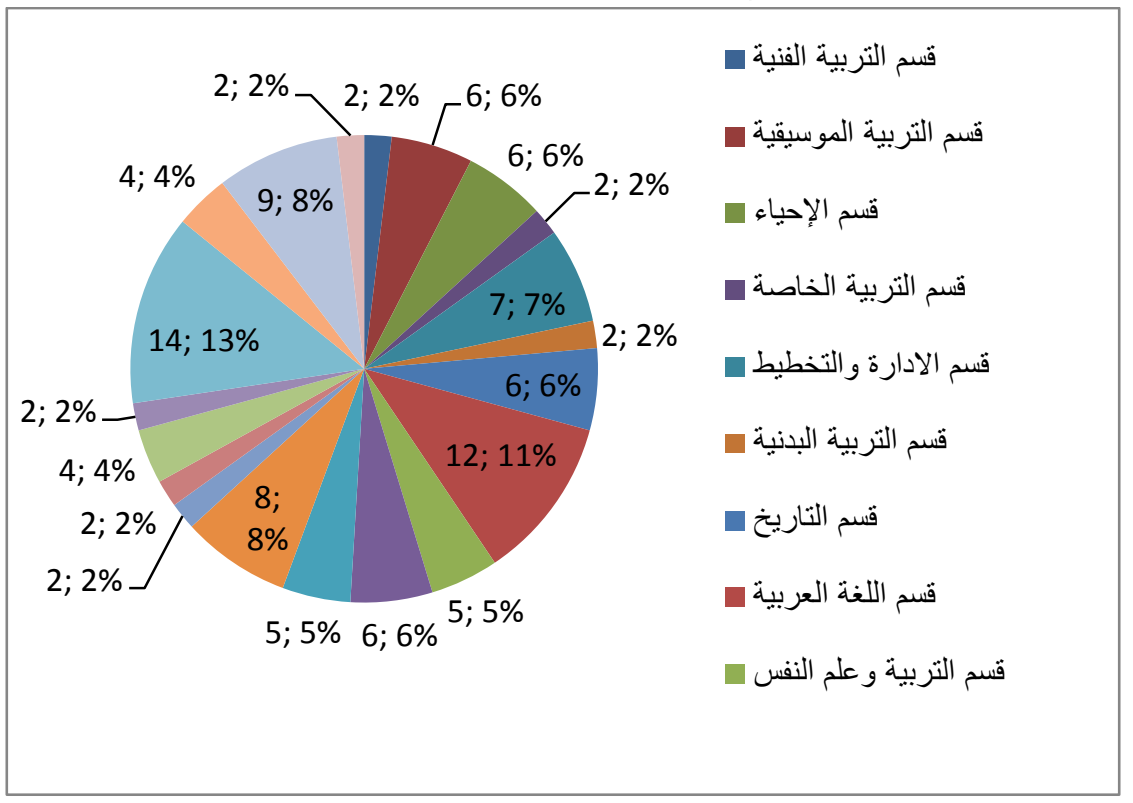

* المصدر : قسم التسجيل بكلية التربية

جدول 1 عدد الطلبة عينة البحث، موزعة على طلبة كلية التربية، مختارين بصورة عشوائية 


\begin{tabular}{|c|c|c|}
\hline العدد & التخصصات & ت \\
\hline 2 & قسم التربية الفنية & 1 \\
\hline 6 & قسم التربية الموسيقية & 2 \\
\hline 6 & قسم الإحياء & 3 \\
\hline 2 & 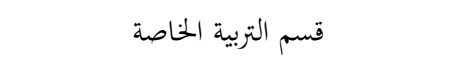 & 4 \\
\hline 7 & قسم الادارة والتخطيط & 5 \\
\hline 2 & 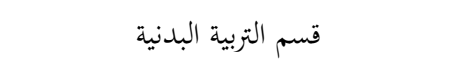 & 6 \\
\hline 6 & 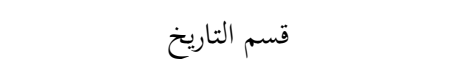 & 7 \\
\hline 12 & قسم اللغة العربية & 8 \\
\hline 5 & قسم التربية وعلم النفس & 9 \\
\hline 6 & 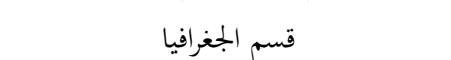 & 10 \\
\hline 5 & 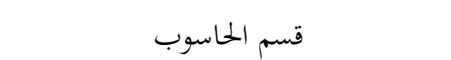 & 11 \\
\hline 8 & قسم الخدمة الاجتماعية & 12 \\
\hline 2 & قسم الدراسات الإسلامية (أصول الدين) & 13 \\
\hline 2 & قسم الدراسات الإسلامية (شريعة) & 14 \\
\hline 4 & 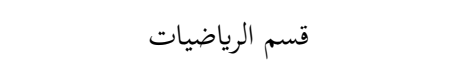 & 15 \\
\hline 2 & قسم الكيمياء & 16 \\
\hline 14 & 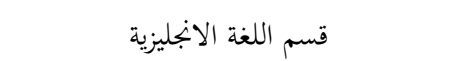 & 17 \\
\hline 4 & قسم رياض الأطفال & 18 \\
\hline 9 & قسم معلم الفصل & 19 \\
\hline 2 & 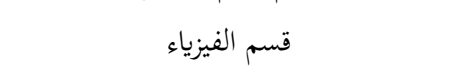 & 20 \\
\hline 106 & المجمـوع & \\
\hline
\end{tabular}

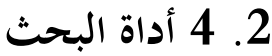

من أجل تحقيق هدف البحث تم اعتماد مقياس (مهدي أحمد الطاهر) المطبق في المملكة العربية السعودية للعام الجامعي (1991م) ، والذي يقيس ابجاهات المعلمين نخو مهنة التدريس. 


\section{صدق أداة البحث}

يقصد بالصدق أن يقيس الاختيار فعلاً ما يقصد أن يقيسه للتأكد من صدق مضمون الأداة، ومدى ملاءمتها للأهداف التي وضعت من أجلها، واعتمد الباحثان الصدق الظاهري للأداة، وذلك بعرض المقياس بشكله الأول المكون من (42) فقرة على جمموعة من المحكمين بلغ عددهم (12) عضو هيئة تدريس من مختلف الأقسام بكلية الآداب، حيث طلب منهم بيان صحة صياغة وصلاحية الفقرات التي تمثل ابحاهات طلبة كلية التربية نحو مهنة التدريس وعلاقتها بمتغير الجنس. وفي ضوء توجيهاقم تم الأخذ بملاحظاهم وإجراء التعديلات المطلوبة، حيث تم حذف (14) فقرة، وهي: (2-9-16-1617-18-20-29-31-32-34-36-36-36-41-41)، وأصبح عدد الفقرات بعد الحذف (28) فقرة، وتم إضافة فقرتين، كما تم تعديل صياغة بعض الفقرات، وأصبحت الأداة تتسم بدرجة مقبولة من الصدق الظاهري، وبذلك أصبحت الأداة بصورتا النهائية تتكون من (30) فقرة، واختير مدرج الإجابة الخماسي (موافق بشدة، موافق، غير متأكد،

$$
\text { 2. } 5 \text { أوافق، لا أوافق بشدة). }
$$

1. الاطلاع على الأدبيات والدراسات السابقة لإرساء الإطار النظري للبحث الحالي والاستفادة منه.

2. اعتماد مقياس الباحث (مهدي أحمد الطاهر) المطبق في المملكة العربية السعودية، للعام الجامعي (1991م)، وعرضه على مجموعة المحكمين للتأكد من صدق عباراته. 3. استخراج ثبات المقياس. 
4. اختيار عينة من مجتمع البحث المتكون من جميع طلبة كلية التربية - جامعة مصراتة، وبلعت عينة البحث(106) طالب وطالبة.

5. تطبيق أداة البحث على العينة الأساسية من طلبة كلية التربية. 6. إجراء التحليل الاحصائي باستخدام الأساليب الإحصائية المناسبة. 7. ال عرض النتائج وتفسيرها.

8. تقديم التوصيات والمقترحات في ضوء نتائج البحث المتوصل إليها.

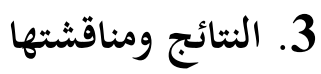

3. 1 للتحقق من نتيجة السؤال الرئيسي في البحث الحالي ونصه: ما ابتاهات طلبة كلية

التربية نحو مهنة التدريس وعلاقتها بمتغير الجنس؟- قام الباحثان باستخدام اختبار (t)، واستخدام المتوسط الحسابي لإيجاد الفروق بين الذكور والإناث، حول ابحاهاقم نهو مهنة التدريس، وفيما يلي عرض نتائج البحث الحالي للسؤال الرئيسي في البحث.

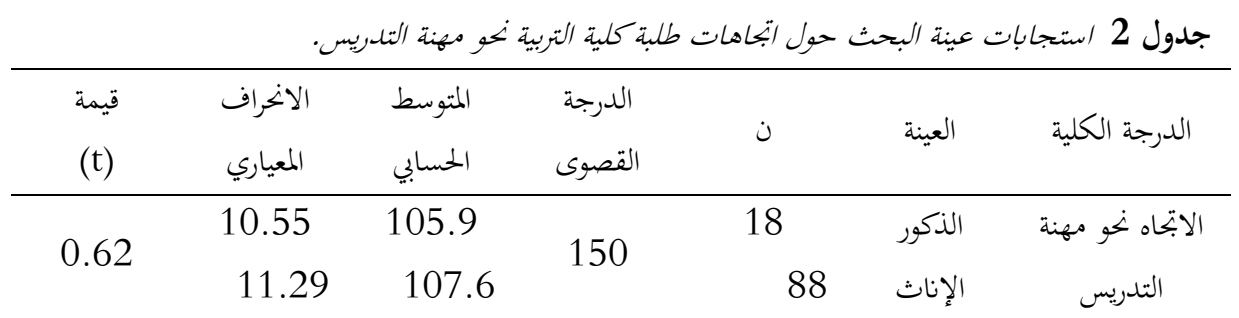

بالنظر إلى الجدول السابق يتضح أنه لا فروق بين الذكور والإناث حول الاتحاه نحو

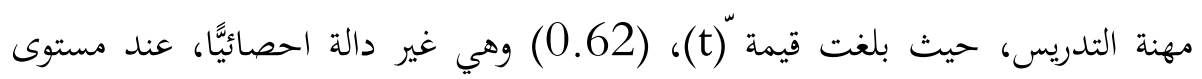
دلالة (0.05)، وبالنظر إلى قيمة المتوسط الحسابي نجد أن عينة الإناث بلغ متوسط استجاباهما (107.6)، ومتوسطها أعلى من متوسط الذكور التي بلغ (105.9)، علمًا بأن الدرجة القصوى لإجابات المفحوصين على هذا المجال تبلغ (150)، مما يعني أن 
ابحاهات طلبة كلية التربية نحو مهنة التدريس إيجابية، وكانت ابتاهات الإناث نهو مهنة التدريس أكثر إيجابية من الذكور، وهذه النتيجة تتفق مع دراسة توفيق شاهين (1990)، ودراسة منى الأزهري (1988)، ودراسة يوسف الأحرش (1996)، ويمكن تفسير ذلك بوجود ابحاهات إيجابية لدى طلبة كلية التربية نحو مهنة التدريس، وهذه النتيجة انعكاس لامتلاك الأساتذة لشخصية قوية قادرة على المواجهة، وقدرقم على تيسير المعلومة وتسهيلها، وقدرقم على التواصل الجيد مع الطلبة، وامتلاكهم لمهارة توصيل المعلومة، و تأثيرهم القوي على الطلبة؛ لذلك فإن أغلب الطلبة يتجهون لمهنة التعليم متأثرين بحبهم لأستاذتم، و تأثرهم بكم كخبراء في مجال تخصصطم، الأمر الذي انعكس على شعور الطلبة برغبتهم في ممارسة مهنة التدريس بعد التخرج. 3. 2 وللتحقق من السؤال الفرعي الأول للبحث الحالي الذي نص على: هل توجد فروق بين عينتي الذكور والإناث في نظرقم الشخصية لمهنة التدريس؟ ، قام الباحثان باستخدام اختبار (t)، واستخدام المتوسط الحسابي لإيجاد الفروق بين الذكور والإناث حول ابتاهاتم نحو النظرة الشخصية لمهنة التدريس، وفيما يلي عرض نتائج البحث الحالي لمبعد الأول في الاستبانة.

\begin{tabular}{|c|c|c|c|c|c|c|}
\hline & & & tis & & $/ / a$ & جدول 3 /ستح \\
\hline قيمة & الانخراف & المتوسط & الدرجة & & & Lif \\
\hline$(\ddot{\mathrm{t}})$ & المعياري & الحسابي & القصوى & 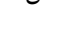 & & \\
\hline \multirow{2}{*}{0.53} & 3.6 & 30.1 & \multirow[t]{2}{*}{40} & 18 & الذكور & النظرة الشخصية \\
\hline & 4.5 & 30.6 & & 88 & الإناث & نحو المهنة \\
\hline
\end{tabular}

بالنظر إلى الجـدول أعـلاه يتضـح أنه لا فـروقَ بــن الـذكور والإناث في نظرقم الشخصية نخو مهنة التدريس، وكانت قيمة (t)، (0.53) وهي غير دالة احصائيَّا، وبالنظر 
إلى قيمة المتوسط الحسابي نجد أن عينة الإناث بلغ متوسط استجاباتا (30.6)، وقيمتها أعلسى مـن قيمـة الـذكور الـتي بلغـت (30.1)، علمًا بأن الدرجـة القصـوى لإجـابات المفحوصسين على هذا المجال تبلغ (40)، مـا يعني أن ابتحاهـات طالبـات كلية التربية نحو النظرة الشخصية لمهنة التدريس أكثر إيبابيـة مـن الذكور وهـذه النتيجـة تتفق مع دراسة يوسف الأحرش (1996)، ودراسة مـنى الأزهـري (1988)، وتختلف مع دراسـة أحمد الغامدي، (1995)، وهذه النتيجة تعني بأن الطالبات لهن ابتحاه إيجابي نهو مهنة التدريس، والرغبة في ممارستها أكثر من الذكور، فهذه الرغبة تأتي بعد وجود شعور وجـداني بالحبب لئب الذي تكنه الطالبات لمهنة التدريس، ومعلومات وتفكير مسبق على ما تتمتع به المهنة من مـزايا وصعوبات، وكـل مـا يتعلق بهـا، وقـد تعـود إلى التزام الطالبـات بمواظبـة حضـورهن

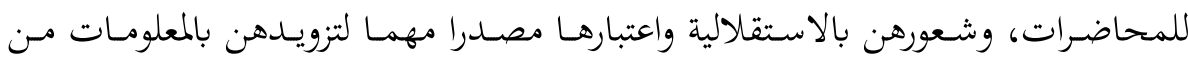
جهة، واعتبارهـا مصدر رزق والشعور بالثقة مـ جهة أخرى، وهذا لا يعني عدم امتلاك الذكور أي ابتحاه إيجابي نحو مهنة التدريس، بل لديهم اتجاه إيجابي نحو مهنة التدريس إلّا أها بدرجة أقل من الإناث، ويرجح الباحثان أن السبب ذلك توفرُ مِهَنِ أخرى تناسبهم، وهلا فوائد مادية ومعنوية قد ترفع من مكانتهم في المجتمع، مثل العمل في الشركات الخدمية، أو القوات المسلحة.

3. 3 ولتحقق من نتيجة السؤال الثاني الفرعي والذي نص على: هل توجد فروق بين عينتي الذكور والإناث في نظرقم للسمات الشخصية للأستاذ؟، قام الباحثان باستخدام اختبار (t)، واستخدام المتوسط الحسابي لإيجاد الفروق بين الذكور والإناث حول ابتاهاقم نخو السمات الشخصية لمهنة التدريس ورصدت النتائج في الجدول رقم 4.

جدول 4 استجابات عينة البحث حول السمات الشخصية للأستاذ. 


\begin{tabular}{|c|c|c|c|c|c|c|}
\hline $\begin{array}{l}\text { قيمة } \\
(\tilde{t})\end{array}$ & الانحراف & المتوسط المسابي & القصوى & ن ن & العينة & البعد الثاني \\
\hline \multirow[b]{2}{*}{0.08} & 4.4 & 21.2 & \multirow[t]{2}{*}{30} & 18 & الذكور & السمات \\
\hline & 3.3 & 21.1 & & 88 & الإناث & للأستاذ الشتصية \\
\hline
\end{tabular}

بالنظر إلى الجمدول أعلاه يتضح أنه لا فروق بين الذكور والإناث في السـمات

الشخصية للأستاذ، وكانت قيمة (t)، (0.08) وهي غير دالة احصائيَّا، وبالنظر إلى قيمة المتوسط الحسابي نجد أن عينة الذكور بلغ متوسط استجاباتها (21.2)، وقيمتها أعلى من قيمة الإناث التي بلغت (21.1)، علمًا بأن الدرجة القصوى لإجابات المفحوصين على هذا المجال تبلغ (30)، مما يعني أن السمات الشخصية للذكور أكثر إيجابية مـ الإناث، وهـذه النتيجـة تتفق مع بعض الدراسـات السـابقة منهـا دراسـة طـارق إبراهيم (1978)، وتختلف مع دراسة شاهين (1990)، وقد يعزى ذلك إلى اعتقادهم بسهولة مارسة هذه المهنة ،وقد يعود إلى زيادة اهتمامهم بكسن المظهر وحسن التعامل مع الاساتذة بمـا يليق بثقافـات الطلبة مـن ناحيـة، وبثقافة المجتمع مـن ناحية أخرى، وقـد يرجع إلى زيادة فرص اللقاء بين الطلبة الذكور والاساتذة خارج المبنى الجامعي، وقدرقم على العمل فترات طويلة أكثر من الإناث. 3. 4 وللتحقق من نتيجة السؤال الثالث الفرعي والذي نص على: هل توجد فروق بين عينتي الذكور والإناث في نظرةم للتقييم الشخصي لقدراته الخاصة؟، قام الباحثان باستخدام اختبار (t)، واستخدام المتوسط الحسابي لإيجاد الفروق بين الذكور والإناث حول ابحاهاتم نحو التقييم الشخصي لقدراته الخاصة، ورصدت النتائج في الجدول رقم 5. 


\begin{tabular}{|c|c|c|c|c|c|c|}
\hline $\begin{array}{l}\text { قيمة } \\
(\ddot{\mathrm{t}})\end{array}$ & الانحراف & المتوسط & القصوى & ن ن & العينة & البعد الثالث \\
\hline \multirow{2}{*}{0.28} & 3.4 & 31.8 & \multirow{2}{*}{45} & 18 & الذكور & التقييم الشخصي \\
\hline & 4.4 & 32.1 & & 88 & الإناث & لقدراته الخاصة \\
\hline
\end{tabular}

بالنظر إلى الجدول أعلاه يتضح أنه لا فروق بين الذكور والإناث في التقييم الشخصي لقدراته الخاصة، حيث بلغت قيمة (t)، (0.28)، وهي غير دالة احصائيا، عند مستوى دلالة 0.05\%، وبالنظر إلى قيمة المتوسط الحسابي نجد أن عينة الإناث بلغ متوسط استجاباتها (32.1) وقيمتها أعلى من قيمة الذكور التي بلغت (31.8)، علما بأن الدرجة القصوى لإجابات المفحوصين على هذا المجال تبلغ (45)، مما يعني أن التقييم الشخصي للقدرات الخاصة بالإناث أكثر إيجابية من الذكور، وقد يعزى ذلك إلى اعتبار الطالبات الفشل خطوة إيجابية لتحقيق النجاح، وتحليهن بالهزيمة والصبر والإصرار، والتعلم من الدروس السابقة، والخبرات لمزاولة مهنة التدريس أكثر من الذكور. 3. 5 وللتحقق من نتيجة السؤال الرابع الفرعي والذي نص على: هل توجد فروق بين عينتي الذكور والإناث في نظرتم لمستقبل المهنة؟، قام الباحثان باستخدام اختبار (t)؛ واستخدام المتوسط الحسابي لإيجاد الفروق بين الذكور والإناث حول البحاهاقم نحو مستقبل

$$
\text { المهنة، ورصدت النتائج في الجدول رقم } 6 .
$$$$
\text { جدول } 6 \text { يوضح استجابات عينة البحث حول مستقبل المهنة. }
$$

\begin{tabular}{|c|c|c|c|c|c|c|}
\hline $\begin{array}{l}\text { قيمة } \\
(\stackrel{\mathrm{t}}{)}\end{array}$ & الانمراف & المسابي & القصوى الدرجة & ن & العينة & البعد الرابع \\
\hline \multirow{2}{*}{0.41} & 2.2 & 14.1 & \multirow{2}{*}{20} & 18 & الذكور & \multirow{2}{*}{ مستقبل المهنة } \\
\hline & 2.0 & 14.3 & & 88 & الإناث & \\
\hline
\end{tabular}


بالنظر إلى الجدول السابق يتضح أنه لا فروق بين الذكور والإناث حول مستقبل المهنة، وكانت قيمة "(t)، (t) (0.41)، وهي غير دالة احصائياً، وبالنظر إلى قيمة المتوسط الحسابي نجد أن عينة الإناث بلغ متوسط استجاباتا (14.3)، وقيمتها أعلى من قيمة الذكور التي بلغت (14.1)، علمـا بأن الدرجة القصوى لإجـابات المفحوصين على هذا المجال تبلغ (20)، مما يعني أن مستقبل المهنة للإناث أكثر إيجابية من الذكور، على رغم ضعفها لديهم ويمكن تفسير ذلك إلى واقعنـا المعاش، فلم تعد هذه المهنة تطعم الخبز، وتلبي الحاجـات للديهم، هـا مـن الناحية المادية، أمـا مـن الناحية المعنوية فليس لها أي تقدير في المجتمع؟

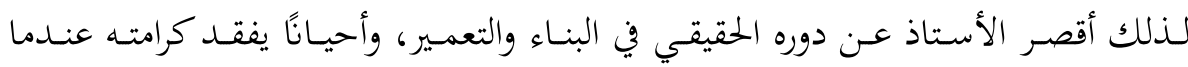
يتعرض للإهانة بأنواعها المختلفة. 3. 6 وللتحقق من نتيجة السؤال الخامس الفرعي الذي نص على: هل توجد فروق بين عينتي الذكور والإناث في نظرة المجتمع نحو المهنة؟، قام الباحثان باستخدام اختبار (t)، واستخدام المتوسط الحسابي لإيجاد الفروق بين الذكور والإناث حول البحاهاتم نحو نظرة المجتمع نهو المهنة، ورصدت النتائج في الجدول رقم 7.

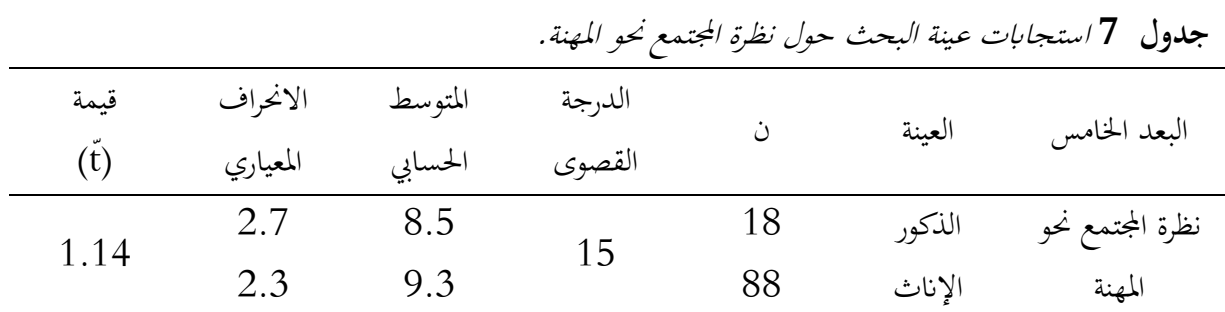

بالنظر إلى الجدول السابق يتضح أنه لا فروق بين الذكور والإناث حول نظرة المجتمع نحو المهنة، حيث بلغت قيمة (t)، (1.14)، وهي غير دالة احصائيا، وبالنظر إلى قيمة المتوسط الحسابي نجد أن عينة الإناث بلغ متوسط استجاباتا (9.3)، وقيمتها أعلى من 
قيمة الذكور التي بلغت (8.5)، علما بأن الدرجة القصوى لإجابات المفحوصين على هذا المجال تبلغ (15)، مما يعني أن نظرة المجتمع نحو المهنة للإناث أكثر إيجابية من الذكور، وهذه النتيجة تتفق مع بعض الدراسات السابقة كدراسة يوسف الأحرش (1996)، ويمكن تفسير الخفاضها عند الذكور مقارنة بالإناث بأن شعورهم بأن المجتمع لم يعطِ المعلم حقه ولم يرعَه الرعاية التي يستحقها؛ لذلك لا بد من تصحيح نظرة المجتمع لمهنة التعليم، ولمكانة المعلم، كذلك النظرة الدونية لمهنة التعليم في هذا الزمن، مع عدم الاهتمام والرعاية للمعلم، ووجودها أكثر لدى الإناث؛ لأغما المهنة الوحيدة التي تناسب المرأة حسب المجتمع المعاث فيه.

\section{4. - (الاستنتاجات والتوصيات}

وجود ابتحاهات إيجابية لطلبة كلية التربية نحو مهنة التدريس، وهذه النتيجة تعتبر جيدة، إلا أن ابتحاهات الإناث نحو مهنة التدريس أكثر من الذكور. وفي ضوء نتائج البحث أوصى الباحثان ببعض التوصيات، منها:

1- العناية والاهتمام بحلقات النقاش وورش العمل من أعضاء هيئة التدريس في جميع التخصصات بالكلية، وتخصيصها لمناقشة ما يستجد في مجال التدريس، وإبراز دور عضو هيئة التدريس الذي يلعبه في تنمية الاتحاه الإيجابي لدى الطلبة لهذه المهنة من خلال تدريسهم مواد تخصصهم.

2- متابعة الأساتذة الملتحقين بالدورات التدريبة، وتقويم مدى استفادقم من هذه الدورات التدريبة، ومدى التحسن في أدائهم، وذلك عن طريق ملاحظة أدائهم لمهنة

$$
\text { التدريس ومتابعة ردود الطلبة حولم. }
$$


3- ضرورة رفع مستوى الأستاذ الجامعي العلمي والثقافي والاقتصادي؛ ليتغير نظرة المجتمع للأستاذ، وترجع النظرة التي فقدها المجتمع نحو مهنة التدريس.

$$
\text { واقترح الباحثان بعض المقترحات، منها: }
$$

1- إجراء دراسات عن أسباب ضعف الاتحاه لدى طلاب التخصصات الأدبية والعلمية

$$
\text { باختلاف مستوياتم الدراسية. }
$$

2- إجراء دراسات عن ابتحاهات طلبة كلية التربية نحو مهنة التدريس وعلاقتها بمتغيرات

$$
\text { أخرى (التحصيل الدراسي، التخصص). }
$$

3- إجراء دراسة حول أخلاقيات مهنة التدريس والصفات التي يجب أن يتحلى بها المعلم. 4- إجراء دراسة حول معرفة العلاقة بين الرغبة في ممارسة مهنة التدريس وعلاقتها بالمعلم

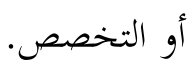

\section{قائمة المراجع}

أبو الضبعان، زكريا إسماعيل، قطيشات، نازك. (2007). اتجاهات طلاب معلم الصف نحو مهنة التدريس وعلاقتها ببعض المتغيرات في جامعة الزيتونة الأردنية الخاصة": رسالة ماجستير

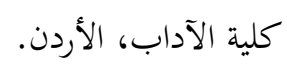

أبو الهيجاء، فؤاد حسن حسين.(2003). التربية الميدانية: دليل عمل المشرفين والطلاب والمعمين. عمان: دار المناهج للنشر والتوزيع.

الأحرش، يوسف أبو القاسم. (1996). اتجاهات المعلمين نحو المهنة وأثرها في تحصيل تلاميذ شهادة إتمام مرحلة التعليم الأساسي في مادة الرياضيات (رسالة ماجستير غير منشورة). 
الأزهري، منى أحمد، (1989)، اتجاهات طلبة كلية التربية بالرس السعودية نحو مهنة التدريس: مجلة الدراسات التربوية. المجلد الخامس، الجزء 21 مصر. حسن، عبدالحكيم محمد أحمد، (2014)، اتباهات طلبة كلية التربية جامعة تعز نحو مهنة التدريس: مركز التأهيل والتطوير التربوي، جامعة تعز، اليمين.

حمادي، أحمد، طحان، محمد خالد. (1996)، الحاجة الإششادية لطلبة جامعة الإمارات: بملة أبحاث اليرموك، سلسلة العلوم الإنسانية والاجتماعية، 1-13-12.

الزغلول، عمار عبد الرحيم (2005)، علم النفس التربوي: دار الكتاب الجامعي، ط:6، عمان،

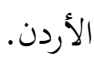

زين الدين، محمود (2004) مبررات /ستعمال مقاييس الاتجاهات عند اختيار الممدسين، جامعة منتوري قسنطية، مجلة العلوم الإنسانية، العدد السادس، سكرة.

شاهين، توفيق سمارة (1990) اتباهات طلبة كليات المجتمع نحو مهنة التلدريس في الأردن (رسالة ماجستير غير منشورة)، جامعة عمان، الأردن.

الطاهر، المهدي أحمد(1991). الاتجاه نحو مهنة التدريس، وعلاقته ببعض المتغيرات الدراسية (رسالة ماجستير غير منشورة) كلية التربية السعودية.

الغامدي، أحمد حمدان (1995). اتجاهات طلاب كلية المعلمين بالرياض نحو مهنة التدريس في المرحلة الابتدائية، وعلاقتها ببعض المتغيرات: مجلة دراسات النفسية. رابطة الاخصائيين النفسيين المصريين القاهرة، مصر.

كريم، محمد أحمد، محمد، عنتر لطفي، بيومي، محمد غازي، عثمان ابتسام مصطفى. (2008م) مهنة التعليم وأدوار المعلم فيها : طباعة دار المعرفة الجامعية. 
المجديل، عبد الله، الشريع، سعد (2012). اتباهات طلبة كليات التربية نحو مهنة التعليم ، دراسة

ميدانية مقارنة بين كلية التربية وجامعة الكويت وكلية التربية الحسكة: جامعة الفرات

$$
\text { أنموذجا، مجلة جامعة دمشق، مج(28)، ع(4)، ص ص 5 56-67. }
$$

مرسي، محمد منير، (1993). مناهج البحث التربوي: بيروت: عالم الكتب للنشر والتوزيع.

Booth-3rb.blogsopt.com 